\title{
Delivery of salbutamol by metered dose inhaler and valved spacer to wheezy infants: effect on bronchial responsiveness
}

\author{
Jane R Clarke, Hazel Aston, Michael Silverman
}

\begin{abstract}
The efficacy of a new valved spacer device, the Babyhaler inhaler (Glaxo) for administering metered dose inhaler treatment via a facemask to infants was assessed. In a double blind, single dose study, salbutamol $(800 \mu \mathrm{g})$ or placebo were given on separate days to 12 sedated, sleeping, wheezy infants during a symptom free interval. Lung function was measured before and after administration and the bronchial response to aerosol challenge with methacholine was then assessed using the squeeze technique. A small increase in heart rate and a drop in arterial oxygen tension followed salbutamol administration. No other change in lung volume or air flow obstruction was detected. Bronchial responsiveness decreased significantly after the administration of salbutamol by Babyhaler, the $\mathbf{P C}_{30}$ (provoking concentration of methacholine causing a $30 \%$ fall in maximal flow at functional residual capacity by the squeeze technique) increasing from a median of $3.8 \mathrm{~g} / 1$ after placebo to $12 \cdot 5 \mathrm{~g} / \mathrm{l}$ after salbutamol.

The Babyhaler is an effective device for administering bronchodilator to wheezy infants. The small scale of the response may be attributable to the uncertain effect of $\beta$ agonists in this population. Furthermore, pulmonary deposition of inhaled aerosols may be reduced in nose breathing, sleeping infants. (Arch Dis Child 1993; 69: 125-129)
\end{abstract}

While there is still controversy about the efficacy of bronchodilators in the management of wheezy infants, there is clinical consensus that some infants do respond to both $\beta$ agonists and to anticholinergic agents. ${ }^{1}$ One of the least satisfactory aspects of bronchodilator treatment in infancy has been the means of administration, with attendant doubts about the dose delivered to the lungs. Inhaled bronchodilators can be given to infants in two ways: from metered dose inhaler (MDI) with spacer device and facemask or by jet nebuliser, a relatively expensive, time consuming, and inconvenient method. Apart from the Aerochamber (Trudell Medical), the currently available spacer devices in the UK are of large volume (10-20 times the tidal volume of an infant) and have valves that tend to stick unless a high respiratory flow rate is generated or the spacer is held vertical. Such devices are not ideal for infants. The Babyhaler (Glaxo) device has been developed to overcome some of these problems. ${ }^{23}$ It consists of a small volume $(350 \mathrm{ml})$ spacer with a facemask to cover the mouth and nose (fig 1) and incorporates a one way valve of low resistance (less than 0.02 $\mathrm{kPa} / \mathrm{l} / \mathrm{s}$ for a flow rate of $75 \mathrm{ml} / \mathrm{s}$ ). The Babyhaler has been used to administer salbutamol to wheezy infants, and has produced a significant improvement in lung function, assessed by airway conductance and thoracic gas volume. ${ }^{23}$

Airway responsiveness has been demonstrated in early infancy, in both wheezy and healthy children. Using partial forced expiratory flow volume curves, obtained by the 'squeeze' technique, bronchoconstriction has been demonstrated by a decrease in maximal flow at residual capacity ( $\left.\max _{\mathrm{FRC}}\right)$, in response to both methacholine and histamine delivered by aerosol..$^{+8}$ Nebulised bronchodilators have been shown to protect against such challenge, ${ }^{49}$ even in the absence of a clear bronchodilator effect.

The purpose of this study was to investigate whether inhaled salbutamol aerosol could be effectively delivered by the Babyhaler device, by measuring the change in lung function and the degree of protection against methacholineinduced bronchoconstriction in recurrently wheezy infants.

\section{Patients and methods}

PATIENTS

Fifteen infants, aged 8-23 months, were recruited from the paediatric asthma clinic. All had a history of recurrent wheezing of at least one months' duration, but had been free of upper respiratory tract symptoms for four weeks. None had evidence of any congenital or systemic disorder or cystic fibrosis. All prescribed medication, including bronchodilator, sodium cromoglycate and inhaled steroids, was stopped at least 24 hours before each study day. Such treatment was permitted during the interval of at least 48 hours between the two study days. Infants were studied while asleep after sedation with triclofos sodium $(150 \mathrm{mg} / \mathrm{kg})$. Each infant received both placebo and salbutamol $800 \mu \mathrm{g}$ by Babyhaler, double blind and in random order on separate days, after baseline lung function tests and before methacholine challenge.

The study had approval from the hospital ethics committee and parental consent was obtained for all subjects.

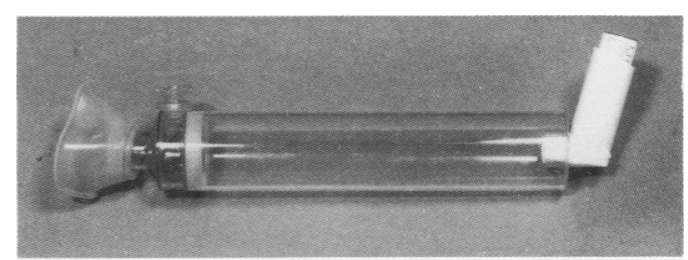

Figure 1 Babyhaler and mask. 


\section{LUNG FUNCTION}

Partial expiratory flow volume (PEFV) curves were obtained using the squeeze technique, as the infant slept in the supine position. Forced expiration was induced by rapidly inflating a snugly fitting, polythene thoracoabdominal jacket (medical engineering department, Royal Postgraduate Medical School, Hammersmith Hospital, London), with the arms enclosed, at end tidal inspiration. ${ }^{101}$ Jacket inflation pressure was measured with a pressure transducer (Validyne MP45). From occlusion tests at end inspiration, the static pressure transmission to the pleural space with this jacket is $56-80 \%$ of the applied pressure. ${ }^{12}$ Flow was recorded with a low resistance screen pneumotachograph (medical engineering department, Royal Postgraduate Medical School, Hammersmith Hospital, London) and facemask (Rendell-Baker Soucek, size 1, Ambu International), connected to a pressure transducer (Validyne MP45). A rim of silicone putty (Carter) was applied around the mouth and nose, and to the facemask, to provide an airtight seal. The flow signal was digitally integrated with respect to time to give the volume. All signals were digitised $(100 \mathrm{~Hz})$ and stored on computer (Compaq deskpro 386/20e). PEFV curves were computer constructed and analysed (RASP Software, Physiologic Ltd) to find the maximal flow at a lung volume corresponding to functional residual capacity $\left(\dot{V}_{\text {max }} \text { FRC }\right)^{13}$ During baseline measurements the jacket pressure was increased from $25 \mathrm{~cm}$ $\mathrm{H}_{2} \mathrm{O}$ by increments of $5 \mathrm{~cm} \mathrm{H} \mathrm{O}$ until flow at functional residual capacity (FRC) had reached a stable maximum, or until the maximum jacket pressure of $80 \mathrm{~cm} \mathrm{H}_{2} \mathrm{O}$ had been reached. A mean baseline value of $\dot{V} \max _{F R C}$ was derived from three technically satisfactory baseline measurements made at the optimal jacket pressure. Thereafter the same jacket pressure was used throughout the challenge procedure.

The FRC was determined by helium dilution technique, using a low dead space $(600 \mathrm{ml})$ water filled infant spirometer (Leiden) and helium analyser (Morgan md2-FRC, PK Morgan). Equilibration was ensured by waiting until the helium concentration was stable (up to six minutes), or there had been minimal change over at least two minutes. A $60 \mathrm{~g}$ weight was briefly applied to the bell to ensure no leak and to verify equilibration. The final helium concentration was obtained by extrapolating the final linear portion of the plot of helium concentration against time back to the point in time at which a decline in helium concentration was first detected. ${ }^{14}$ This compensates for any slow decline in helium concentration due to helium dissolving in blood and tissues. An oxygen analyser (IMI B-D Electrodyne, Becton Dickinson included in the circuit served as an additional method of checking for leaks within the circuit, which could otherwise have been inadvertently compensated for by excess oxygen input. Three measurements of FRC were made, allowing a washout time at least as long as the equilibration period between measurements. The mean FRC was calculated before and after the aerosol had been given.

\section{BABYHALER DEVICE AND MDI ADMINISTRATION}

Subjects were randomly allocated to two groups at the first visit, so that half received salbutamol $800 \mu \mathrm{g}$ at the first visit and placebo at visit 2 , at least 48 hours later. The remainder received the study drugs in the reverse order. The same procedure was used for both visits. After baseline FRC measurements and PEFV curves had been obtained, the facemask and putty were removed. The aerosol treatment was administered as eight actuations from the study inhaler, which contained either salbutamol $100 \mu \mathrm{g}$ per actuation or placebo. One puff from the study inhaler was actuated into the Babyhaler device while holding the spacer in a horizontal position. The facemask was immediately placed over the infant's mouth and nose, and held in place until the infant had taken five breaths from the device. This procedure was then repeated until all eight actuations from the study inhaler had been administered. Fifteen minutes after inhalation of the study aerosol, three FRC measurements and

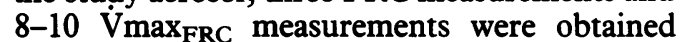
followed by the methacholine challenge.

\section{METHACHOLINE CHALLENGE}

Aerosols of normal saline, as a control, followed by doubling concentrations of methacholine were administered for one minute each by a Wright nebuliser, with $8 \mathrm{l} / \mathrm{min}$ airflow (nebuliser output $0.16 \mathrm{ml} / \mathrm{min}$ by weighing, aerosol aerodynamic mass median diameter $1 \cdot 0-1 \cdot 5 \mu \mathrm{m}^{15}$ ). The facemask, pneumotachograph removed, acted as a chamber, into which the aerosol was directed over the mouth and nose of the sleeping infant. Commencing with $0.5 \mathrm{~g} / \mathrm{l}$, doubling concentrations of methacholine were administered at five minute intervals, until either a $30 \%$ fall from the $\dot{V}_{\text {max }}$ FRC after the Babyhaler had been observed or the maximum methacholine concentration of $32 \mathrm{~g} / \mathrm{l}$ had been reached. Commencing 30 seconds after completion of each nebulisation, 6-10 squeeze manoeuvres were then carried out. All curves were analysed, and the three technically satisfactory curves with the highest values were chosen to give a mean $\dot{V} \max _{\text {FRC }}$ for each dose.

The provoking concentration of methacholine producing a $30 \%$ fall in $\dot{\mathrm{V}} \max _{\mathrm{FRC}}\left(\mathrm{PC}_{30}\right)$ from the mean value after Babyhaler was calculated by linear interpolation from dose response plots of $\dot{\operatorname{Vmax}}{ }_{\mathrm{FRC}}$ against $\log$ methacholine concentration for each study.

\section{MONITORING}

Transcutaneous oxygen tension $\left(\mathrm{PtcO}_{2}\right)$ was monitored using a combined (oxygen and carbon dioxide) skin electrode (TCM3, Radiometer), at $44^{\circ} \mathrm{C}$ placed on the thigh. The electrode was calibrated with $20.9 \%$ oxygen and $5 \%$ carbon dioxide before each study. After each nebulisation, values were noted every 30 seconds. The change in $\mathrm{PtcO}_{2}$ was taken as the maximum deviation from the baseline level occurring between two and five minutes after each dose. The transcutaneous carbon dioxide tension $\left(\mathrm{PtcCO}_{2}\right)$ was recorded concurrently. Oxygen saturation $\left(\mathrm{SaO}_{2}\right)$ was monitored using a pulse 
oximeter (Ohmeda Biox 3740) applied to the big toe. The change in $\mathrm{SaO}_{2}$ was taken as the maximum deviation from the baseline level occurring between two and five minutes after each dose of methacholine.

\section{ANALYSIS}

Because some of the changes in lung function occurring after the Babyhaler were not normally distributed and the $\log \mathrm{PC}_{30}$ data were censored, they were compared with Wilcoxon matched pairs test.

The study design enabled a difference of two doubling concentrations in $\mathrm{PC}_{30}$ to be detected between the placebo and salbutamol studies, with a power of greater than $90 \%$.

\section{Results}

Three infants were withdrawn from the study. Two had severe baseline airway obstruction shown by flow limitation during tidal breathing, so bronchial challenge was precluded. One infant vomited before baseline measurements, so his study was terminated. He subsequently developed measles. Three infants woke during methacholine challenge on the second visit. Data from the prechallenge lung function tests in these subjects are included and from one of the subjects for methacholine challenge (see below). Of the 12 infants (six boys and six girls) included in the prechallenge analysis, seven had a history of maternal smoking and eight had a family history of atopy. All 12 had previously taken ipratropium bromide and three were taking intermittent $\beta_{2}$ agonists by MDI and Multispacer (Medicaid). One subject was receiving sodium cromoglycate treatment and three inhaled corticosteroids, also given by MDI and Multispacer.

The mean ( $95 \%$ confidence interval, $\mathrm{Cl}$ ) vital statistics for the 12 infants were: weight $10.5 \mathrm{~kg}$ ( 9.6 to 11.5$)$, length $75.7 \mathrm{~cm}(73.1$ to 78.2$)$, and age 13.6 months $(10.9$ to 16.3$)$. The median standardised residuals (SD score) $(95 \% \mathrm{CI})$ for baseline values of $\operatorname{Vmax}_{\text {FRC }}$ and FRC on the control day were $-0.63(-1.82$ to 0.68$)$ and $-1.63(-2.56$ to -0.30$)$ respectively, in relation to the reference range of Tepper et al. ${ }^{16}$

Neither $\dot{V} \max _{\mathrm{FRC}}$ nor FRC changed significantly with the placebo or salbutamol (table). There were no significant changes in $\mathrm{SaO}_{2}$ after administration of the Babyhaler plus MDI. After salbutamol administration, there was a tendency for the heart rate to increase, but this trend did not reach statistical significance. After both placebo and salbutamol, there was a fall in $\mathrm{PtcO}_{2}$ (median difference 0.3 and $0.8 \mathrm{kPa}$;

Lung function data; results are median $(95 \% C I) ; n=12$

\begin{tabular}{|c|c|c|c|c|}
\hline \multirow{2}{*}{. } & \multicolumn{2}{|l|}{ Control day } & \multicolumn{2}{|l|}{ Salbutamol day } \\
\hline & Baseline & After Babyhaler & Baseline & After Babyhaler \\
\hline $\begin{array}{l}\text { Hear rate }() / \mathrm{min}) \\
\mathrm{SaO}_{2}(\%) \\
\mathrm{Ptco}_{2}(\mathrm{kPa})\end{array}$ & $\begin{array}{l}116(107 \text { to } 133) \\
96(95 \text { to } 98) \\
9 \cdot 4(8 \cdot 4 \text { to } 10 \cdot 6)\end{array}$ & $\begin{array}{l}117(111 \text { to } 132) \\
96(95 \text { to } 98) \\
9 \cdot 1(8 \cdot 0 \text { to } 10 \cdot 5)^{\star}\end{array}$ & $\begin{array}{l}115(105 \text { to } 138) \\
96(96 \text { to } 97) \\
9 \cdot 8(8 \cdot 7 \text { to } 10 \cdot 8)\end{array}$ & $\begin{array}{l}127(114 \text { to } 141) \\
96(94 \text { to } 97) \\
9 \cdot 0(7 \cdot 5 \text { to } 10 \cdot 3)^{\star \star}\end{array}$ \\
\hline $\begin{array}{l}V \cdot \max _{(\mathrm{mRC}} \\
\operatorname{FRC}(\mathrm{ml})\end{array}$ & $\begin{array}{l}203(167 \text { to } 258) \\
184(171 \text { to } 199)\end{array}$ & $\begin{array}{l}207(186 \text { to } 256) \\
187(179 \text { to } 196)\end{array}$ & $\begin{array}{l}196(141 \text { to } 291) \\
184(166 \text { to } 216)\end{array}$ & $\begin{array}{l}224(145 \text { to } 324) \\
192(167 \text { to } 211)\end{array}$ \\
\hline
\end{tabular}

Difference compared with baseline on the same day: ${ }^{\star} p=0.01,{ }^{\star \star} p=0.005$.

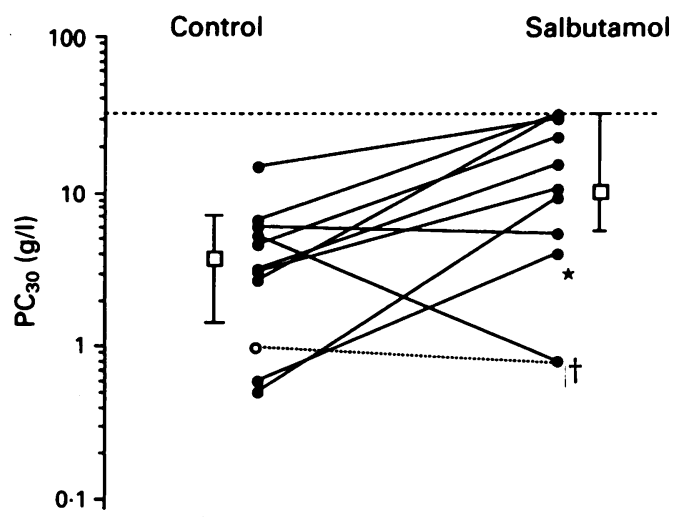

Figure $2 P_{30} \dot{V}_{\max }{ }_{F R C}$ on control and salbutamol study days. Dashed line: $32 \mathrm{~g} / \mathrm{l}$ (maximum concentration given). ${ }^{\star}$ The value after salbutamol is an estimate (see text). tOpen circle and dotted line indicate alternative result for the subject who responded adversely to the control aerosol (see text). Bars: median and $95 \%$ CI; $p<0.05$ compared with control day (Wilcoxon matched pairs test).

$\mathrm{p}=0.01$ and $\mathrm{p}=0.005$ respectively). $\mathrm{PtcCO}_{2} \mathrm{did}$ not change.

All 10 subjects for whom adequate data were available responded to methacholine on the placebo day. This includes data on one subject who woke without any response to methacholine during the salbutamol study, at a concentration of $2 \mathrm{mg} / \mathrm{ml}$. After placebo he responded with a $\mathrm{PC}_{30}$ of $0.6 \mathrm{~g} / 1$. His results were included, $\mathrm{PC}_{30}$ after salbutamol being estimated as $4 \mathrm{~g} / \mathrm{l}$ (the lowest concentration at which a response was possible). Salbutamol significantly decreased the response to methacholine (fig 2). The median values $(95 \% \mathrm{CI})$ for $\mathrm{PC}_{30}$ on control and salbutamol study days were $3.8 \mathrm{~g} / 1(1.6$ to $6 \cdot 1 \mathrm{~g} / \mathrm{l})$ and $12.5 \mathrm{~g} / 1(4.9$ to $31 \mathrm{~g} / \mathrm{l})$ respectively $(\mathrm{p}<0.05)$.

In only one subject was the $\mathrm{PC}_{30}$ significantly lower after salbutamol, compared with placebo. On the placebo study day, this subject had an inexplicable $23 \%$ fall in $\max _{\mathrm{FRC}} 15$ minutes after placebo, which would certainly have influenced the results, leading to a falsely high $\mathrm{PC}_{30}$ on that day. There was no such adverse response to salbutamol. After recalculating using the mean baseline value for $\dot{V} \max _{F R C}$, the $\mathrm{PC}_{30}$ (placebo) for this subject was $1.0 \mathrm{~g} / \mathrm{l}$ and after salbutamol $0.8 \mathrm{~g} / \mathrm{l}$. Using these values, the median $(95 \% \mathrm{CI})$ values for $\mathrm{PC}_{30}$ on the control days became $3.1 \mathrm{~g} / 1(0.8$ to $6 \cdot 1)$, two doubling dilutions less than after salbutamol $(p<0 \cdot 02)$.

\section{Discussion}

This study demonstrates the effectiveness of salbutamol given by the Babyhaler device in protecting against methacholine-induced bronchoconstriction in infants. A previous study in our laboratory showed that salbutamol given in a much larger dose $(2.5 \mathrm{mg})$ by nebuliser was effective in reducing the bronchial response to histamine by at least 16-fold in wheezy infants.' Baseline lung function was not improved after bronchodilator in the present or previous study. This could be because at the time of study, all the infants were asymptomatic.

Other studies have shown spacer devices to be effective, both in reducing symptoms and also producing improved lung function. Two previous studies have demonstrated an improvement in thoracic gas volume and airway conduct- 
ance after salbutamol given by the Babyhaler to infants with recurrent wheeze, with cystic fibrosis or recovering from respiratory distress syndrome. ${ }^{23}$ Mallol and colleagues used a valveless spacer device to give fenoterol and ipratropium bromide to acutely wheezy infants, and found significant improvement in clinical score. ${ }^{17}$ Other groups have given wheezy infants ipratropium bromide via the Nebuhaler (Astra Pharmaceuticals) with a mask (tipped up to open the valve $)^{18}$ and terbutaline via a polystyrene coffee cup as a spacer ${ }^{19}$ and demonstrated both clinical and physiological improvements. Another spacer, the Aerochamber, has been modified specifically for infants. It has a low resistance valve $\left(3 \mathrm{~cm} \mathrm{H}_{2} \mathrm{O} / \mathrm{l} / \mathrm{s}\right)$, with a small mask dead space $(35 \mathrm{ml})$ and an internal volume of $135 \mathrm{ml}$. In a two week crossover study in infantile asthma, active treatment with only 100 $\mu \mathrm{g}$ of salbutamol via the Aerochamber was superior to placebo in reducing symptoms. ${ }^{20}$

We used a relatively high dose of salbutamol, suspecting that pulmonary drug delivery to our sleeping, nose breathing infants was likely to be significantly lower than in mouth breathing subjects. ${ }^{21}$ The actual spacer design, relative to the size of the infant, is crucial in determining what proportion of the dose administered reaches the airways. Using sodium cromoglycate as a marker, in children aged 9-36 months using a larger volume (approximately $620 \mathrm{ml}$ ), relatively inefficient, valved Multispacer with a facemask, it has been estimated that only $0.3 \%$ of the dose administered into the spacer actually reaches the airways. ${ }^{21}$

Using the Babyhaler spacer, significant improvement in lung function was seen in $57 \%$ of infants when $400 \mu \mathrm{g}$ salbutamol was given, compared with $93 \%$ infants when $600 \mu \mathrm{g}$ was given. ${ }^{3} \mathrm{~A}$ preliminary study we performed before this one, using only half the dose of salbutamol $(400 \mu \mathrm{g})$, did not show a significant reduction in bronchial responsiveness to histamine. There is clearly a dose dependent effect. A dose of $800 \mu \mathrm{g}$ may seem excessive, but the modest and statistically insignificant increment in heart rate suggests that the effective dose delivered to the lower respiratory tract was probably suboptimal.

The size of a spacer device must be a compromise between aerosol concentration, which will be greatest in a small volume device, and aerosol loss through impaction, which will be smallest with a large volume. Another equally important factor is emptying time, which depends on tidal volume and breathing frequency. Everard and colleagues designed a model using a ventilator to generate respiratory cycles across a filter, and administered sodium cromoglycate from a MDI into a Nebuhaler, an Aerochamber, and a coffee cup in a study comparing different spacer devices. ${ }^{22}$ They showed that at low tidal volumes the high aerosol concentration in the smaller chamber enhanced drug delivery, but at the higher tidal volumes delivery was better from the larger chamber. However multiple doses from MDIs are not without problems, producing a high concentration of propellant that theoretically should evaporate, but which may cause adverse effects. The deterioration in oxygenation that we found after placebo could have been a response to the propellant. Several infants coughed, after placebo, probably in response to the cold propellant they inhaled from the Babyhaler.

There is some evidence that repeated doses of inhaled bronchodilator may be more effective than a single large dose. This could be the explanation for the efficacy in clinical trials ${ }^{20}$ in contrast to single dose, physiological studies. In the study of Kraemer $e t$ al repeated doses of salbutamol at five minute intervals were used. ${ }^{3} \mathrm{~A}$ study looking at the response of infants with acute asthma to nebulised salbutamol showed a significant improvement in symptoms after two doses of salbutamol given one hour apart, ${ }^{23}$ although this could have been simply an effect of dosage.

Our study design looked at bronchial responsiveness induced in the laboratory by methacholine, rather than at infants during an acute wheezy episode. Using conventional techniques to assess infant lung function, it is not usually possible to examine infants during an acute attack. Unlike pulmonary function testing in cooperative, older children we test infants while asleep, and sedation is not recommended during an acute wheezy episode. Assessing bronchodilatation and bronchoconstriction using the squeeze technique can be misleading. V $\max$ is measured using FRC as the reference point. If hyperinflation (an increase in FRC) occurs during induced bronchoconstriction, the response to methacholine, as assessed by changes in $\dot{V} \max F$ FrC will tend to be underestimated..$^{24}$ The converse changes are likely to occur after bronchodilator, but the tendency will still be to underestimate the response.

We measured lung volumes using the helium dilution technique, and in our study showed no significant response after bronchodilator therapy. The problem with gas dilution techniques in infants with severe airway obstruction, is that FRC may be underestimated, due to slow and incomplete mixing of the helium within poorly ventilated areas of the lung. In a study looking at changes in FRC in response to bronchodilator treatment in young asthmatic children, Greenough and colleagues found an increase in FRC in some children after bronchodilator treatment, ${ }^{26}$ presumably because after bronchodilatation, there was improved access of helium to areas of the lung with previously poor ventilation. Other children had a fall in FRC consistent with a reduction of hyperinflation after bronchodilatation. This causes problems in interpreting any change in FRC, or indeed apparent lack of change, after bronchodilator treatment.

This study shows that salbutamol, given by the Babyhaler device, was effective in preventing methacholine induced bronchoconstriction in infants with recurrent wheezing. The device is potentially useful for administering any agent by MDI, where oral treatment is inappropriate and where nebulisation (of suspensions for instance) is relatively ineffective. Therapeutic regimens for infants have not yet been adequately evaluated. Our results suggest either that unit doses in currently commercially available MDIs are too low to be optimal for administration to 
infants by spacer devices, or that the ideal small, valved spacer and facemask system has yet to be developed.

This work was supported by Glaxo; we thank Dr Michelle Clay for her help. We are indebted to Mr R H Cumberland, Physiologic Ltd, for computer software and Mr N Levy and Mr N Sen for technical assistance.

1 Warner JO, Gotz M, Landau LI, et al. Asthma: a follow up statement from an international paediatric asthma consensus group. Arch Dis Child 1992; 67: 240-8

2 Kraemer R, Frey U, Sommer CW, Rossi E. Short-term effect of albuterol, delivered via a new auxiliary device, in wheezy infants. Am Rev Respir Dis 1991; 144: 347-51.

3 Kraemer R, Birrer P, Modelska K, Casaulta Aebischer C, Schoni MH. A new baby-spacer device for aerosolized bchoni MH. A new baby-spacer device for aerosolized bronchodilator administration in infants with bro
monary disease. Eur F Pediatr 1992; 151: 57-60.

4 Tepper RS. Airway reactivity in infants: a positive response to methacholine and metaproterenol. F Appl Physiol 1987; 62 $155-9$.

5 Prendiville A, Green S, Silverman M. Bronchial responsiveness to histamine in wheezy infants. Thorax 1987; 42: 92-9.

6 LeSouef P, Geelhoed G, Turner DJ, Morgan SEG, Landau LI. Response of normal infants to inhaled histamine. Am Rev Respir Dis 1989; 139: 62-6.

7 Stick SM, Arnott J, Turner DJ, Young S, Landau LI, LeSouef PN. Bronchial responsiveness and lung function in Lesouef PN. Bronchial responsiveness and lung function in recurren.

8 Clarke JR, Reese A, Silverman M. Bronchial responsiveness and lung function in infants with lower respiratory tract illness over the first six months of life. Arch Dis Child 1992 67: 1454-8.

9 Prendiville A, Green S, Silverman M. Airway responsiveness in wheezy infants: evidence for functional beta adrenergic receptors. Thorax 1987; 42: 100-4.

10 Silverman M, Prendiville A, Green S. Partial expiratory flow volume curves in infancy: technical aspects. Bulletin Europeen de Physiopathologie Respiratoire 1986; 22. 257-62.

11 Beardsmore CS, Godfrey S, Silverman M. Forced expiratory flow volume curves in infants and young children. Eur Respir $\mathcal{F} 1989 ; 2$ (suppl 4): 154s-9.

12 LeSouef PN, Hughes DM, Landau LI. The effect of compression pressure on forced expiratory flow in infants. $\mathcal{f}$ Appl sion pressure on forced expi

13 Clarke JR, Silverman M. Partial expiratory flow volume curves. In: Dezateaux CA, Fletcher ME, Rabette PS, Stanger LJ, Stocks J, eds. A manual of infant lung function testing. London: Institute of Child Health, 1991: 83-92.

14 Merth I, Quanjer PH, Verschragen GJ. Functional residual capacity by the helium dilution methods. In: Dezateaux CA, Fletcher ME, Rabette PS, Stanger LJ, Stocks J, eds. $A$ manual of infant lung function testing. London: Institute of manual of infant lung function

15 Juniper EFJ, Cockcroft DW, Hargreave FE. Histamine and methacholine inhalation tests: tidal breathing method. Laboratory procedure and standardisation. Canadian Thoracic Society. Lund, Sweden: AB Draco, 1991.

16 Tepper RS, Morgan WJ, Cota K, Wright A, Taussig LM and GHMA Paediatricians. Physiologic growth and development of the lung during the first year of life. Am Rev Respir Dis 1986; 134: 513-9.

17 Mallol J, Barrueto L, Girardi G, Toro O. Bronchodilator effect of ipratropium bromide in infants with acute wheezing: use of MDI with a spacer device. Pediatr Pulmonol 1987; 3: of $M 52-6$.

18 O'Callaghan C, Milner AD, Swarbrick A. Spacer device with face mask attachment tor giving bronchodilators to intants with asthma. $B M F$ 1989; 298: 160-1.

19 Yuksel B, Greenough A, Maconochie I. Effective bronchodilator treatment by a simple spacer device for wheezy premature infants. Arch Dis Child 1990; 65: 782-5.

20 Connor WT, Dolovich MB, Frame RA, Newhouse MT. Reliable salbutamol administration in 6- to 36-month-old children by means of a metered dose inhaler and aerochamber with mask. Pediatr Pulmonol 1989; 6: 263-7.

21 Salmon BS, Wilson NM, Silverman M. How much aerosol reaches the lungs of wheezy infants and toddlers? Arch Dis reaches the lungs of whec

22 Everard ML, Clark AR, Milner AD. Drug delivery from holding chambers with attached facemask. Arch Dis Child 1992; 67: 580-5.

23 Bentur L, Canny G, Shields MD, et al. Controlled trial of nebulized albuterol in children younger than 2 years of age with acute asthma. Pediatrics 1992; 89: 133-7.

24 Maxwell DL, Prendiville A, Rose A, Silverman M. Lung volume changes during histamine induced bronchoconstriction in recurrently wheezy infants. Pediatr Pulmonol 1988; 5: 145-51.

25 Clarke JR, Reese A, Silverman M. Changes in FRC during histamine challenge in infants. Am Rev Respir Dis 1991; 143: A24.

26 Greenough A, Pool J, Price J. Changes in functional residual capacity in response to bronchodilator therapy among young asthmatic children. Pediatr Pulmonol 1989; 7: 8-11. 